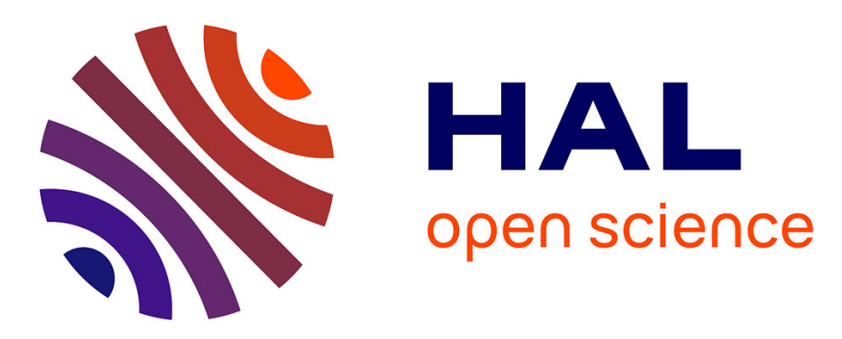

\title{
Chirality induction to achiral molecules by silica-coated chiral molecular assemblies
}

Antoine Scalabre, Yutaka Okazaki, Balamurugan Kuppan, Thierry Buffeteau, Fabrizio Caroleo, Gabriele Magna, Donato Monti, Roberto Paolesse, Manuela Stefanelli, Sylvain Nlate, et al.

\section{To cite this version:}

Antoine Scalabre, Yutaka Okazaki, Balamurugan Kuppan, Thierry Buffeteau, Fabrizio Caroleo, et al.. Chirality induction to achiral molecules by silica-coated chiral molecular assemblies. Chirality, 2021, 33, pp.494 - 505. 10.1002/chir.23339 . hal-03341139

\section{HAL Id: hal-03341139 \\ https://hal.science/hal-03341139}

Submitted on 16 Sep 2021

HAL is a multi-disciplinary open access archive for the deposit and dissemination of scientific research documents, whether they are published or not. The documents may come from teaching and research institutions in France or abroad, or from public or private research centers.
L'archive ouverte pluridisciplinaire HAL, est destinée au dépôt et à la diffusion de documents scientifiques de niveau recherche, publiés ou non, émanant des établissements d'enseignement et de recherche français ou étrangers, des laboratoires publics ou privés. 


\title{
Chirality induction to achiral molecules by silica-coated chiral molecular assemblies
}

\author{
Antoine Scalabre $^{1}$ | Yutaka Okazaki ${ }^{2}$ | Balamurugan Kuppan ${ }^{1}$ |

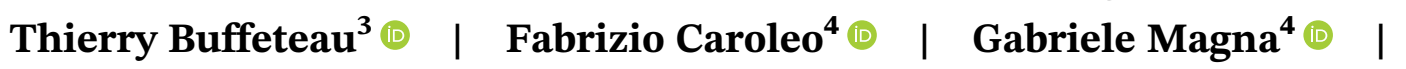 \\ Donato Monti $^{4} \odot$ | Roberto Paolesse ${ }^{4} \odot$ | Manuela Stefanelli ${ }^{4} \odot$ |

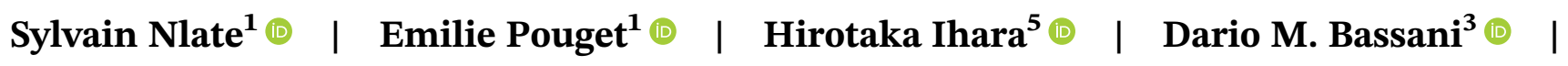 \\ Reiko Oda ${ }^{1}$ \\ ${ }^{1}$ Institute of Chemistry \& Biology of Membrane \& Nanoobjects (UMR 5248 CBMN), CNRS - Université de Bordeaux - Bordeaux INP, Pessac, France \\ ${ }^{2}$ Graduate School of Energy Science, Kyoto University, Kyoto, Japan \\ ${ }^{3}$ Institut des Sciences Moléculaires (UMR5255 ISM), CNRS - Université de Bordeaux, Talence, France \\ ${ }^{4}$ Dept. of Chemical Science and Technologies, University of Rome Tor Vergata, Rome, Italy \\ ${ }^{5}$ Department of Applied Chemistry and Biochemistry, Kumamoto University, Kumamoto, Japan
}

\author{
Correspondence \\ Dario M. Bassani, Institut des Sciences \\ Moléculaires (UMR5255 ISM), CNRS - \\ Université de Bordeaux, 351, cours de la \\ Libération, 33400 Talence, France. \\ Email: dario.bassani@u-bordeaux.fr \\ Reiko Oda, Institute of Chemistry \& \\ Biology of Membrane \& Nanoobjects \\ (UMR 5248 CBMN), CNRS - Université \\ de Bordeaux - Bordeaux INP, 2 rue \\ Robert Escarpit, 33600 Pessac, France. \\ Email: reiko.oda@u-bordeaux.fr

\section{Funding information} \\ Kyoto University; European Union's \\ Horizon 2020 research and innovation \\ program, Grant/Award Number: 828779; \\ Université de Bordeaux; Centre National \\ de la Recherche Scientifique; Japan \\ Society for the Promotion of Science, \\ Grant/Award Numbers: 17K05000, \\ 19K15376; ANR, Grant/Award Number: \\ ANR-CONACYT-159884; Japan Science \\ and Technology Agency
}

\begin{abstract}
Hybrid silica-organic nanohelices are used to organize a large variety of nonchiral small organic molecules or inorganic anions to nanometer-sized assemblies. Such chiral organization of achiral molecules induces chiroptical properties as detected by vibrational or electronic circular dichroism (CD), as well as from circularly polarized luminescence (CPL).
\end{abstract}

\section{K E Y W O R D S}

circular dichroism, circularly polarized luminescence, excimer emission, induced chirality, silica nanohelice

\section{1 | INTRODUCTION}

Chiral ions or ionic molecules are attractive owing to their asymmetric catalytic activity, ${ }^{1-4}$ enantioselectivity, ${ }^{5}$ or

[This article is part of the Special Issue: Chirality in France.] their chiroptical properties. ${ }^{6,7}$ Chiral co-crystallization, ${ }^{8}$ chiral molecular assemblies, ${ }^{9-15}$ or confinement of achiral ions in chiral cyclodextrins ${ }^{16}$ can be used to induce chiroptical properties to achiral ions or molecules and/or enhancing chiral signals with promising advantages such as (1) tunability of the chiral properties, (2) versatility of 
choices of chromophores (molecules, ions particles, etc.), and (3) transparency of solutions in the UV-vis region due to the nanometric size of the assemblies. However, addition of guest chromophores to molecular host assemblies can disturb or destroy their chiral organization, giving a significant limitation to this method.

Recently, we reported the formation of hybrid silicacoated chiral crystalline molecular assemblies with controlled handedness (right vs. left) for the induction of circular dichroism (CD) signals to the achiral monoatomic anions, methyl orange, and anthracene carboxylate. ${ }^{17-19}$ The hybrid system used to organize these achiral molecules is based on self-assemblies of gemini surfactants with enantiomeric tartrate counterions, $N, N^{\prime}$ dihexadecyl- $N, N, N^{\prime}, N^{\prime}$-tetramethylethylene diammonium L- or D-tartrate (hereafter, abbreviated as 16-2-16 L- or D-tartrate, (Scheme 1) ${ }^{17,20}$ Depending on the enantiomer of the tartrate counterion, the self-assemblies form righthanded (RH-) or left-handed (LH-) twisted and helical ribbon-like and tubular self-assemblies with a double bilayer in water and some organic solvents. ${ }^{21,22}$ These chiral nanostructures, following transcription into a silica matrix using TEOS, form hybrid organic-inorganic composites. ${ }^{17-19}$ Once the organic assemblies are coated with silica shells, the tartrate anions can be replaced by small or large achiral anionic molecules through ion exchange without destroying the helical morphology of the molecular assemblies (Figure S1). These newly introduced anions are then organized in a chiral environment.

In this study, we extend this approach to a number of different anions in order to demonstrate the generality of this methodology. We also investigate how the confinement of the anions can affect their electronic properties and lead to the emergence of chiroptical properties even with small inorganic anions such as nitrate. We also show how these anions influence the organization of the surrounding molecular assemblies. We show that this approach can be used for luminescent molecules such as pyrene, perylene, and porphyrin (TPPS) ${ }^{16}$ derivatives in order to induce circularly polarized luminescence from the confined achiral anionic fluorophores, in particular through excimer formation in some cases.

\section{2 | MATERIALS AND METHODS}

\section{1 | Materials}

All reagent grade solvents and chemicals for the synthesis of 16-2-16 gemini tartrate were received from Merck and used without further purification. All external molecules for the integration in the hybrid structures were received from TCI and used without further purification.

\section{2 | Synthesis of PTCTK}

The synthesis of perylene-3,4,9,10-tetracarboxylic acid tetra potassium salt (PTCTK) was performed as previously reported, ${ }^{23,24}$ starting from commercial perylene-3,4,9,10-tetracarboxylic dianhydride. Typically, $5 \mathrm{~g}$ were poured into $150 \mathrm{ml}$ of ultrapure water containing $6 \mathrm{~g}$ of potassium hydroxide then headed to reflux and reacted for $14 \mathrm{~h}$ before precipitation in a mixture of isopropanol: acetone.

\section{3 | Synthesis of 16-2-16 gemini tartrate and organic}

The synthesis of 16-2-16 gemini tartrate was performed as previously reported ${ }^{16,19}$ starting from $N, N, N^{\prime}, N^{\prime}$ tetramethylethylenediamine and 1-bromohexadecane then exchanging the bromide counterion to acetate using silver acetate then to enantiopure tartrate using tartaric acid. The powder of 16-2-16 gemini tartrate was dissolved into water at $70^{\circ} \mathrm{C}(1 \mathrm{mM})$ then aged for 4 days at $20^{\circ} \mathrm{C}$ typical used quantities are $20 \mathrm{mg}$ of powder for $28 \mathrm{ml}$ of ultrapure water. The powder containing L-tartrate enantiomer forms a suspension of right-handed nanohelices, whereas the one with $\mathrm{D}$-tartrate forms a suspension of left-handed structures. The good formation of the structures is confirmed using TEM.

\section{4 | Preparation of hybrid}

A silica shell is formed around the organic helices through polycondensation of tetraethylorthosilicate (TEOS). To do so, TEOS need first to be hydrolyzed in an acidic medium. One and a half milliliters of TEOS were typically dispersed in $30 \mathrm{ml}$ of $10 \mathrm{mM} \mathrm{L}$ or D tartaric acid solution for $7 \mathrm{~h}$. Then, TEOS solution was added in the suspension of organic helices. After overnight reaction, hybrid helices are washed by water at $4^{\circ} \mathrm{C}$ using centrifugation $(12 \mathrm{~min} / 3893 \mathrm{~g})$. Afterward, tip sonication $(130 \mathrm{~W} / 10 \mathrm{~s})$ was performed in order to have welldispersed suspensions.

\subsection{Ion exchange with inorganic or dye molecules}

The suspensions of Hyb-helix-tart $\left(0.20 \mathrm{mg} \mathrm{ml}^{-1}\right)$ were washed $8-10$ times by $100-\mathrm{mM}$ solution of the potassium or sodium salt of targeted inorganic molecular anions $\left(\mathrm{NO}_{3}{ }^{-}, \mathrm{SCN}^{-}, \mathrm{WO}_{4}{ }^{2-}, \mathrm{CrO}_{4}{ }^{2-}\right.$, and $\left.\mathrm{MnO}_{4}{ }^{-}\right)$using centrifugation $(12 \mathrm{~min} / 3893 \mathrm{~g})$ at $4^{\circ} \mathrm{C}$. It was followed by $8-10$ 
Self-assembling molecule: Cationic gemini surfactant with chiral counterion<smiles>O=C(O)C(=O)O</smiles><smiles>CCCCCCCCCCCCCCCCCCCC</smiles>

16-2-16 tartrate

Achiral anionic guests (1): Inorganic molecular anions<smiles></smiles>

Achiral anionic guests (2): Anionic polyaromatic chromophores<smiles>O=C(O)Cc1ccc2ccc3cccc4ccc1c2c34</smiles>

PAA<smiles>O=S(=O)(O)c1ccc2ccc3cccc4ccc1c2c34</smiles>

PSA<smiles></smiles><smiles>CCOC(=O)c1ccc2c3ccc(C(=O)OC(C)=O)c4c(C(=O)O)ccc(c5ccc(C(=O)O)c1c52)c43</smiles>

PTCTK<smiles>CS(=O)(=O)c1ccc2c(c1)C(=O)/C(=C1\Nc3ccc(S(=O)(=O)O)cc3C1=O)N2</smiles>

IC<smiles>Nc1c(N=Nc2ccc(-c3ccc(N=Nc4cc(S(N)(=O)=O)c5ccccc5c4N)cc3)cc2)cc([N+](=O)[O-])c2ccccc12</smiles>

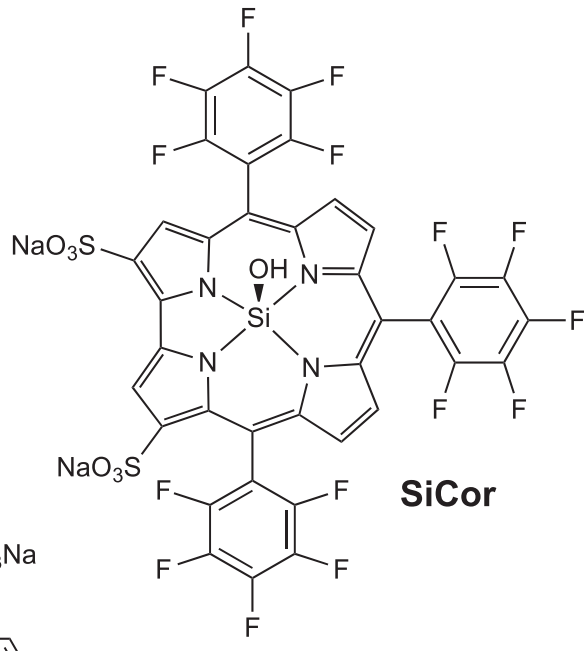

SCHEME 1 Molecular structure of 16-2-16 tartrate, achiral inorganic molecular anions, and achiral anionic or acidic polyaromatic chromophores used in this study 
FIGURE 1 Transmission electron microscopy (TEM) image of hybrid nanohelices and schematic representation of these structures

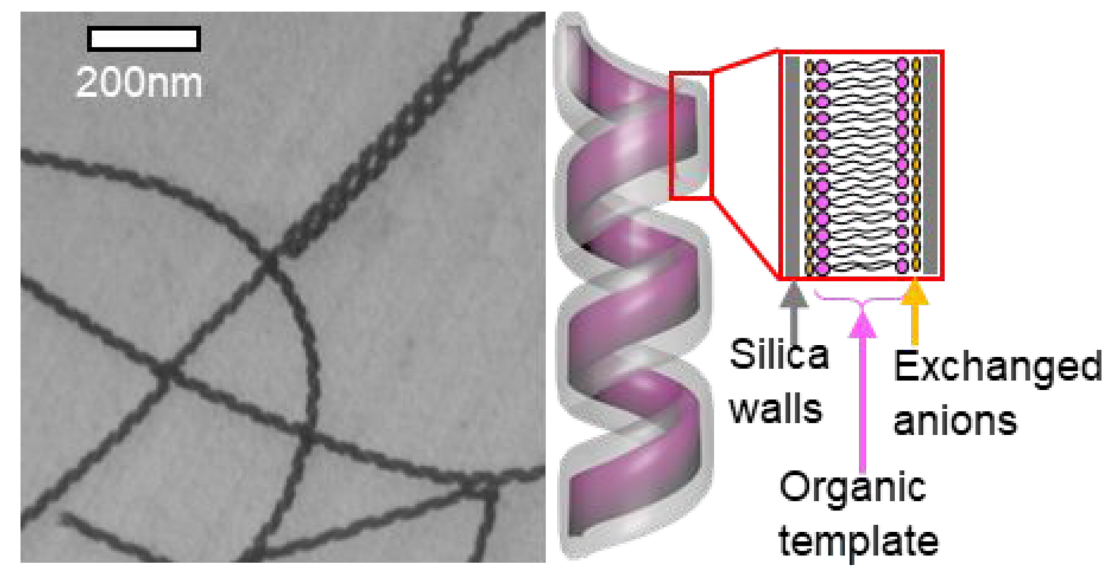

washings by ultrapure water $\left(4^{\circ} \mathrm{C}\right)$ to remove the excess of molecule. In order to insert chromophore in the structure, the counterions of Hyb-helix-tart were first replaced by chloride ions, by washing with $100-\mathrm{mM} \mathrm{KCl}$, until no tartrate was detected using $\mathrm{CD}$ followed by washing with ultrapure water $\left(4^{\circ} \mathrm{C}\right)$ five times. The concentration of Hyb-helix-Cl was then adjusted to the desired value $\left(0.238\right.$ or $\left.0.095 \mathrm{mg} \mathrm{ml}^{-1}\right)$ by addition of ultrapure water and various quantity of a dyes were added to obtain a concentration of $20-200 \mu \mathrm{M}$. This solution was then kept for $2 \mathrm{~h}$ on roller mixer at $6^{\circ} \mathrm{C}$.

\subsection{IR and VCD spectral}

In order to avoid the intense absorption peaks of $\mathrm{H}_{2} \mathrm{O}$ in the $1500-1800 \mathrm{~cm}^{-1}$ and the $3000-4000 \mathrm{~cm}^{-1}$ regions, $\mathrm{D}_{2} \mathrm{O}$ was used as a solvent for all infrared (IR) and vibrational circular dichroism (VCD) spectral measurements. $\mathrm{L}^{-}$and $\mathrm{D}$-helix-tart as well as $\mathrm{L}^{-}$and D-helix- $\mathrm{NO}_{3}$ aqueous solutions $\left(2.0 \mathrm{mg} \mathrm{ml}^{-1}\right)$ were washed with $\mathrm{D}_{2} \mathrm{O}$ at $4^{\circ} \mathrm{C}$ using centrifuge (3893g, $12 \mathrm{~min})$. The concentration of these samples was adjusted to $20 \mathrm{mg} \mathrm{ml}^{-1}$. IR spectra were recorded with a Thermo-Nicolet Nexus 670 FTIR spectrometer, at a resolution of $4 \mathrm{~cm}^{-1}$, by coadding 50 scans. Samples were held in a demountable $\mathrm{CaF}_{2}$ cell with fixed path length of $55 \mu \mathrm{m}$ (Biotools ${ }^{\mathrm{TM}}$, Biotools). All IR spectra were shown with subtraction of solvent background. VCD measurements were performed using a ThermoNicolet Nexus 670 FTIR spectrometer equipped with a VCD optical bench. In this optical bench, the light

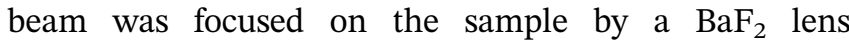
(191-mm focal length), passing an optical filter, a $\mathrm{BaF}_{2}$ wire grid polarizer (Specac), and a $\mathrm{ZnSe}$ photoelastic modulator (Hinds Instruments, Type II/ZS50). The light was then focused by a $\mathrm{ZnSe}$ lens (38.1-mm focal length) onto a $1 \times 1 \mathrm{~mm}^{2} \mathrm{HgCdTe}$ (ThermoNicolet, MCTA* E6032) detector. VCD spectra were recorded at a resolution of $4 \mathrm{~cm}^{-1}$, by coadding 24,000 scans (8-h acquisition time). Baseline corrections of the VCD spectra were performed by subtracting the raw VCD spectra of a $\mathrm{D}_{2} \mathrm{O}$ solvent. The photoelastic modulator was adjusted for a maximum efficiency in the mid-IR region at $1400 \mathrm{~cm}^{-1}$. Calculations were performed via the standard ThermoNicolet software, using Happ and Genzel apodization, de-Haseth phase-correction and a zerofilling factor of one.

\subsection{CD spectral measurements}

JASCO J-815 instrument was used for CD spectral measurements. The hybrid suspensions were put in a quartz cell. All the data discussed in this work has linear dichroism (LD) less than 0.001 (delta OD) and high tension (HT) less than $600 \mathrm{~V}$ to ensure the identity of the $\mathrm{CD}$ signal. The detail measurement condition for all inorganic anions $\left(\mathrm{NO}_{3}{ }^{-}, \mathrm{SCN}^{-}, \mathrm{WO}_{4}{ }^{2-}, \mathrm{CrO}_{4}{ }^{2-}\right.$, and $\mathrm{MnO}_{4}{ }^{-}$) and some organic anions (Py, IC, and CR) are as follows. Scan speed: $200 \mathrm{~nm} \mathrm{~min}^{-1}$; bandwidth: $1 \mathrm{~nm}$, digital integration time: $0.5 \mathrm{~s}$; temperature: $20^{\circ} \mathrm{C}$. The measurement conditions for other organic anions (1-pyreneacetic acid [PAA], 1-pyrenesulfonic acid [PSA], PTCTK, TPPS, and corrole [SiCor]) are as follows. Scan speed: $100 \mathrm{~nm} \mathrm{~min}{ }^{-1}$; bandwidth: $2 \mathrm{~nm}$, digital integration time: 1 s.; temperature: $4^{\circ} \mathrm{C}$.

\section{8 | Circularly polarized luminescence spectral measurements}

Various hybrid suspensions were put in a quartz cell with $10-\mathrm{mm}$ path length. The measurements were conducted with the scan speed at $100 \mathrm{~nm} \mathrm{~min}^{-1}$, with a data integration time of 4 s. Circularly polarized 
luminescence (CPL) spectral measurement was performed at $4^{\circ} \mathrm{C}$ using a JASCO CPL-300. Excitation and emission bandwidths and high tension of the detector were adapted for each sample as follows: for PSA, both band widths are set to $10 \mathrm{~nm}$ with a high tension of $680 \mathrm{~V}$; for PTCTK, both band widths are set to $15 \mathrm{~nm}$ with a high tension of $930 \mathrm{~V}$; and for TPPS, the slit width were set at $3000 \mu \mathrm{m}$ with a high tension of $600 \mathrm{~V}$.

For the chirality induction from gemini to anions, it is crucial that the chiral organization of gemini molecules are maintained inside the hybrid structures. This organization is closely related to the temperature of phase transition which is, around $35^{\circ} \mathrm{C} .^{17,19}$ As we wanted to keep the chiral organization of gemini during the introduction of achiral anions, we chose to measure the CD and CPL at the temperature farthest as possible from the transition temperature in order to maintain the stability of gemini organization in the hybrid structure, which is, $4^{\circ} \mathrm{C}$.

\section{3 | RESULTS AND DISCUSSION}

We selected two types of achiral anionic guests: (1) inorganic molecular anions with different shapes such as trigonal planar nitrate $\left(\mathrm{NO}_{3}{ }^{-}\right)$, linear thiocyanate $\left(\mathrm{SCN}^{-}\right)$, tetrahedral orthotungstate (VI) $\left(\mathrm{WO}_{4}{ }^{2-}\right)$, chromate (VI) $\left(\mathrm{CrO}_{4}{ }^{2-}\right)$, and permanganate (VII) $\left(\mathrm{MnO}_{4}{ }^{-}\right)$; and (2) anionic polyaromatic chromophores (Scheme 1).

The method for ion exchange is detailed in the experimental section below. Briefly, self-assembled nanohelices of 16-2-16 L- or D-tartrate were coated with a thin layer of silica via sol-gel transcription (denoted as Hyb-helix-tart). ${ }^{17-19}$ Unreacted TEOS was removed by repeated centrifugation and washing with water at $4^{\circ} \mathrm{C}$. The choice of the solvent and temperature is of high importance to keep the organic self-assembly inside the silica shell. The structures obtained are denoted Hyb-helix-tart $\left(0.20 \mathrm{mg} \mathrm{ml}^{-1}\right)$. Subsequently, the inorganic anions were inserted directly in Hyb-helix-tart by ion exchange: $100-\mathrm{mM}$ solution of the corresponding potassium or sodium salt was added to the sample, followed by washing $8-10$ times using $4^{\circ} \mathrm{C}$ water. This allows tartrate to be exchanged by inorganic anions, leading to the formation of Hyb-helix $-\mathrm{NO}_{3}{ }^{-}$and so on. For the insertion of organic dyes, a preliminary step is needed to replace tartrate by chloride in order to facilitate the introduction of the dye: Hyb-helix- $\mathrm{Cl}$ are first formed via ion exchange. ${ }^{19}$ The Hyb-helix- $\mathrm{Cl}\left(0-0.25 \mathrm{mg} \mathrm{ml}^{-1}\right)$ are then mixed with the chromophores having concentrations adjusted to reach the desired gemini/dye ratio. All of the dye is incorporated, and no further washing is necessary.
As shown in Figure 2, induced CD (ICD) signals were observed from all of the inorganic anions at wavelengths maxima of their UV-vis absorption spectrum. As expected, inversion of the helical chirality of the silica template ( $\mathrm{RH}$ vs. $\mathrm{LH}$ ) provides mirror-image ICD signals. These results indicate that the silica-coated molecular assembled nanohelix can induce chiroptical properties to various achiral inorganic anions.

In the case of the Hyb-helix- $\mathrm{NO}_{3}{ }^{-}$system, we also performed detailed IR spectroscopic studies along with VCD. Exchanging tartrate anions by nitrate anions results in the disappearance of the IR absorption bands at $1611 \mathrm{~cm}^{-1} \quad\left(\nu_{\mathrm{a}} \mathrm{CO}_{2}{ }^{-}\right), \quad 1383 \mathrm{~cm}^{-1} \quad\left(\nu_{\mathrm{s}} \mathrm{CO}_{2}{ }^{-}\right), \quad$ and $1340 \mathrm{~cm}^{-1}\left(\delta \mathrm{C}^{*} \mathrm{H}\right)$, characteristic of tartrate. This is accompanied by the appearance of a broad intense band around $1360 \mathrm{~cm}^{-1}$ that is characteristic of the $\nu_{3}$ vibration of the nitrate anion, thereby confirming the exchange of tartrate by $\mathrm{NO}_{3}{ }^{-}$. The VCD band in the $1400-1300 \mathrm{~cm}^{-1}$ region of $\mathrm{Hyb}$-helix- $\mathrm{NO}_{3}{ }^{-}$in $\mathrm{D}_{2} \mathrm{O}$ (Figure 3B, top) confirms the induced chirality in the $\mathrm{NO}_{3}{ }^{-}$anions due to their chiral organization inside the silica nanohelices.

The 3000-2800 and $1520-1450 \mathrm{~cm}^{-1}$ regions of the IR spectra group provide vibrational information from the hydrocarbon chains of the gemini surfactant (Figure 3). From this, we can extract information pertaining to the packing of 16-2-16 surfactants. In the case of Hyb-helixtart, the bending modes of the methylene groups $\left(\delta \mathrm{CH}_{2}\right)$ at 1471 and $1466 \mathrm{~cm}^{-1}$ are split. This is a signature of the highly ordered orthorhombic packing of the hydrocarbon chains of the gemini surfactant, which exhibits a two-fold axis symmetry $\left(\mathrm{C}_{2}\right)$ parallel to the membrane plane and perpendicular to the ribbon axis. ${ }^{20,25}$ These absorption bands merge into one peak at $1469 \mathrm{~cm}^{-1}$ for the Hyb-helix- $\mathrm{NO}_{3}{ }^{-}$system, indicating a transition to a lessordered hexagonal packing which is accompanied by a small shift of $\delta_{\mathrm{a}} \mathrm{CH}_{3}$ peak from 1497 to $1494 \mathrm{~cm}^{-1}$ (Figure 3B, bottom). On the other hand, no significant change was observed for the asymmetric $\left(\nu_{\mathrm{a}} \mathrm{CH}_{2}\right)$ and symmetric $\left(\nu_{\mathrm{s}} \mathrm{CH}_{2}\right)$ stretching vibrations of the alkyl chain of 16-2-16 surfactant at 2919 and $2850 \mathrm{~cm}^{-1}$, respectively (Figure $\mathrm{S} 2$ ). The VCD signals for the gemini surfactant in the $1520-1450 \mathrm{~cm}^{-1}$ region showed a ca. $50 \%$ reduction of intensity, confirming the reduction of the chiral organization of the gemini surfactant as seen from the IR band during $\mathrm{NO}_{3}{ }^{-}$inclusion.

Encouraged by results showing that the Hyb-helix-X systems are capable of inducing chiroptical properties in achiral anions, we then investigated anionic dyes such as pyrene derivatives PAA and PSA, PTCTK as well as TPPS and SiCor derivatives (Scheme 1). These were selected based on their ability to be emissive both in solution and in the solid-state and their strong propensity 

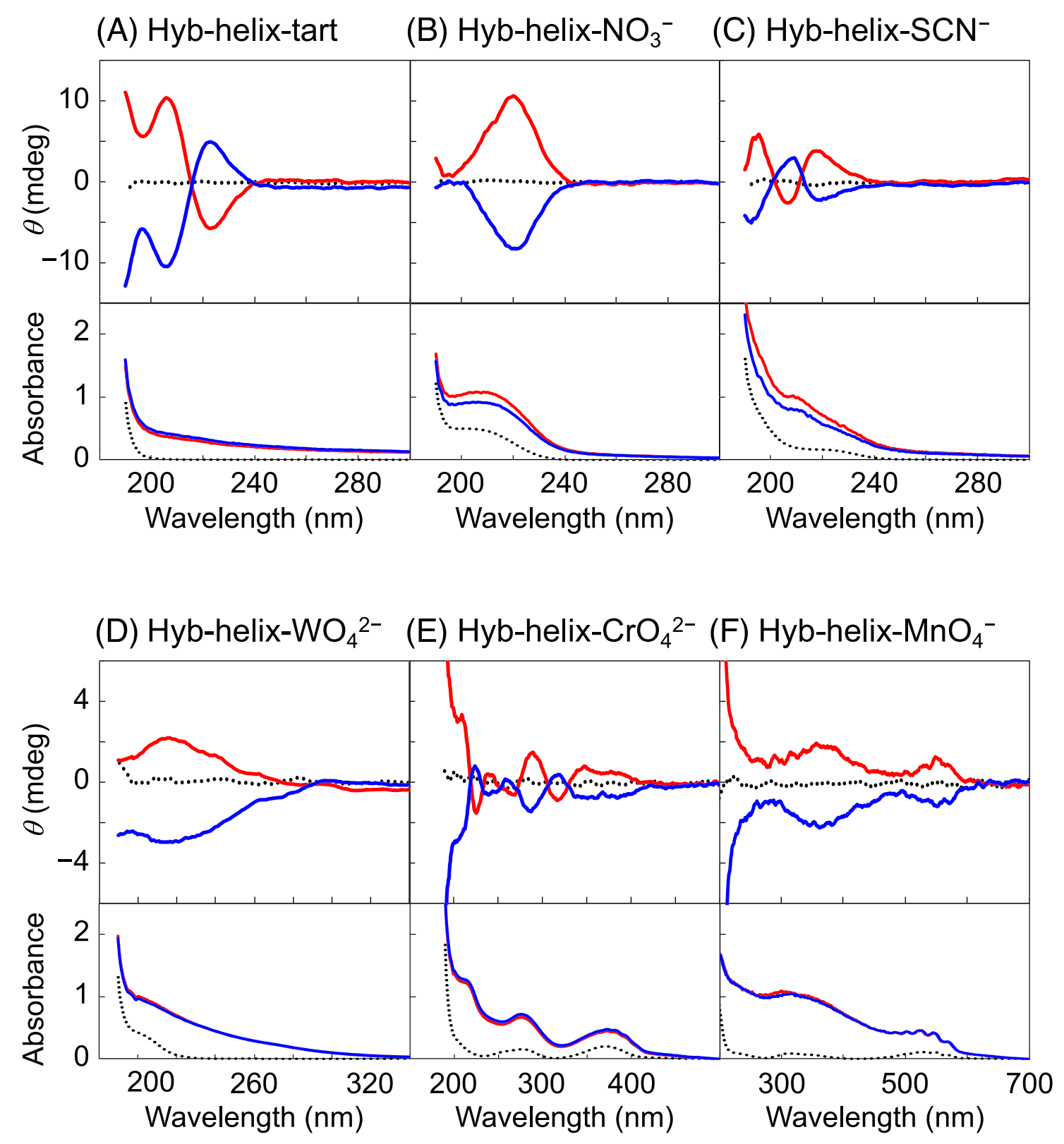

F I G U R E 2 Circular dichroism (CD) (top) and UV-vis absorption (bottom) spectra of RH- (red lines) and LH- (blue lines) Hyb-helix in water (0.20 mg ml${ }^{-1}$ ) obtained by washing with (A) water, (B) $\mathrm{KNO}_{3}$ aq., (C) $\mathrm{KSCN}$ aq., (D) $\mathrm{Na}_{2} \mathrm{WO}_{4}$ aq., (E) $\mathrm{K}_{2} \mathrm{CrO}_{4}$ aq., and (F) $\mathrm{KMnO}_{4}$ aq. Dotted black lines represent water (A) and $50 \mu \mathrm{M}$-inorganic salts $\left(\mathrm{KNO}_{3},(\mathrm{~B}) ; \mathrm{KSCN}_{1}(\mathrm{C}) ; \mathrm{Na}_{2} \mathrm{WO}_{4},(\mathrm{D}) ; \mathrm{K}_{2} \mathrm{CrO}_{4},(\mathrm{E}) ; \mathrm{KMnO}_{4},(\mathrm{~F})\right)$ aqueous solutions, respectively. All samples were measured at $20^{\circ} \mathrm{C}$

towards self-aggregation leading to the efficient induction of chirality in an analogous system as we have shown previously. $^{26}$

For all the organic chromophores, mirrored ICD signals were observed with the use of $\mathrm{RH}$ - versus $\mathrm{LH}$ - hybrid helices (Figure 4). The dissymmetry factor $g$, is defined as

$$
g=\frac{\Delta \varepsilon}{\varepsilon}=\frac{\theta}{32,982 A}
$$

where $\varepsilon$ is molar extinction coefficient and $\theta$ is molar ellipticity (milli degrees), and $\Delta \varepsilon$ are the difference of $\varepsilon$ for left circularly polarized light and right circularly polarized light, and $A$ the absorbance allows a direct comparison of the chiroptical activity of the samples and are presented in Table 1.

We investigated the effect of the dye concentration of PAA, PSA, and PTCTK for the ICD signal. Varying the dye concentrations from 0.02 to $0.2 \mathrm{mM}$ did not result in a significant change in the $g$ factor, which instead 
(A)

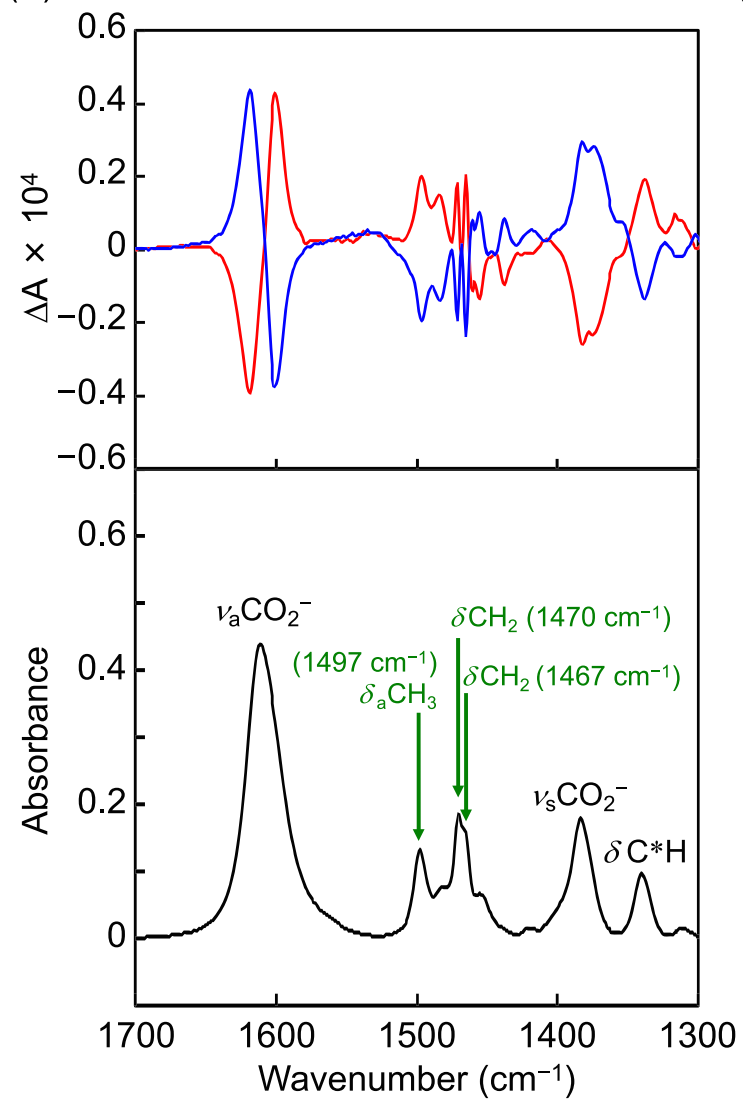

(B)

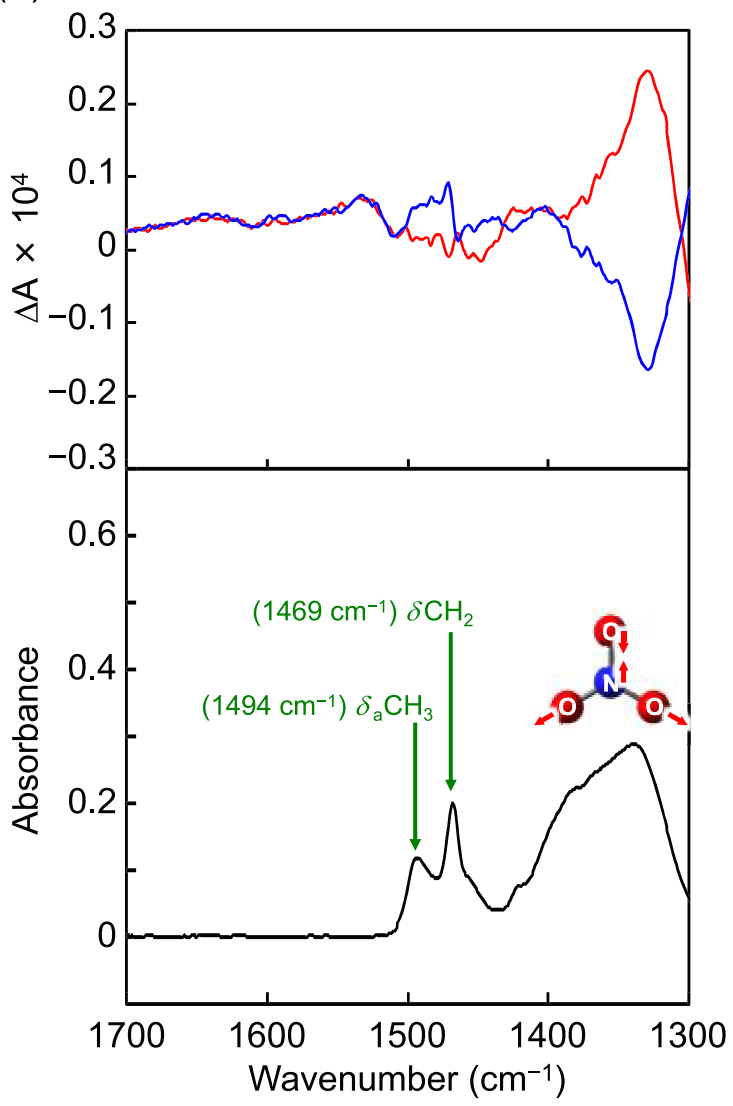

F I G U R E 3 Vibrational circular dichroism (VCD) (top) and infrared (IR) absorption (bottom) spectra of (A) Hyb-helix-tart and (B) Hybhelix- $\mathrm{NO}_{3}$ in $\mathrm{D}_{2} \mathrm{O}$. Red and blue lines represent $\mathrm{RH}$ - and LH- silica-coated molecular assembled nanohelices. The peaks indicated by green arrows are attributed to the gemini surfactant

remained constant $\left(\sim 5 \times 10^{-4}\right)$. This is in stark contrast with our previous observation for dye molecules covalently grafted onto the silica nanohelices, which showed an exponential relationship between $g$ and the concentration of dyes. ${ }^{26}$ We interpret this difference as being due to the different mechanism for chirality induction in the two systems. In the case of dyes grafted onto the silica nanohelices without the presence of the gemini surfactants, the origin of the ICD lies in the interdye interactions and their chiral arrangement. For such ICD to be observed, the dye molecules need to be closely packed, giving an exponential growth of the signal versus surface concentration of the dye. This is also confirmed by the recent results reported by us and others on the chiral aggregation of porphyrin-based systems, which feature sensibly larger $g$ values, that scales with the dimensions of the aggregates. ${ }^{27-29}$ In contrast, when the dyes are incorporated inside the surfactant assembly, the chiral organization of the dyes is induced by the chiral environment of the surfactant. ${ }^{19}$ Therefore, the chirality induced on each dye molecule should be independent of its concentration, as seen herein for the $g$ factor that remains almost constant with increasing dye concentration. Globally, larger $g$ factors were observed for PSA than for PAA that is attributed to the stronger interaction between the less basic sulfonate (PSA) with the quaternary ammonium cation of the gemini surfactant as compared with the carboxylate group in PAA. ${ }^{30,31}$ The ion exchange process followed over 4 days showed faster kinetics for PSA (Figure S8).

The absorbed organic chromophores are emissive and the fluorescence signals originating from the bound dyes can also provide information on their local environment and chirality. ICD signals were observed for all the bound dyes, confirming the chiral induction from the macroscopic host. In contrast, induced circularly polarized luminescence was observed only for PSA, TPPS, and PTCTK (Figure 5). In the case of PSA, when the dye is mixed with hybrid helices, a broad fluorescence peak that is assigned to an emissive excimer appears at approximately $460 \mathrm{~nm}$. This suggests that PSA inside the surfactant assembly can form stacked dimers. Induced CPL (ICPL) originating from these excimers is clearly distinguished from the contribution of the monomer 
(A) Hyb-helix-PAA

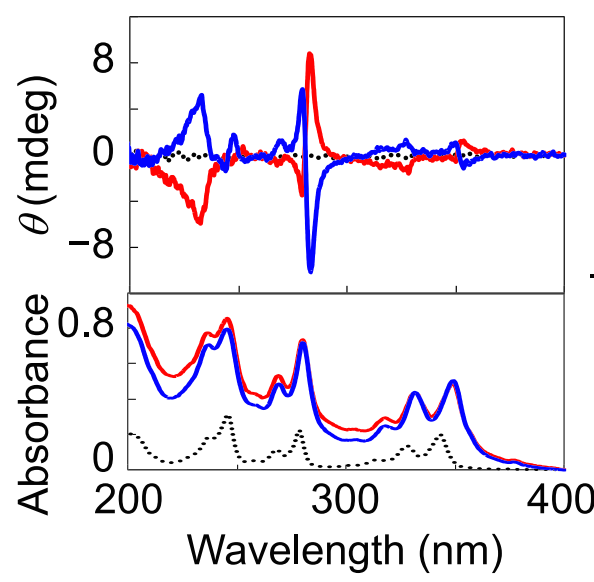

(B) Hyb-helix-PSA

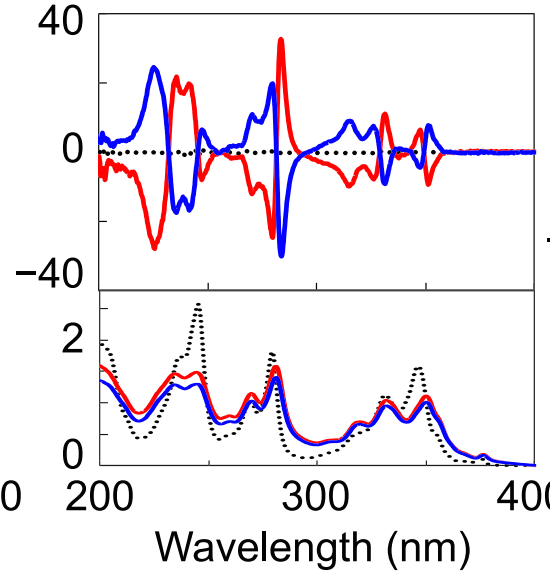

(C) Hyb-helix-Py

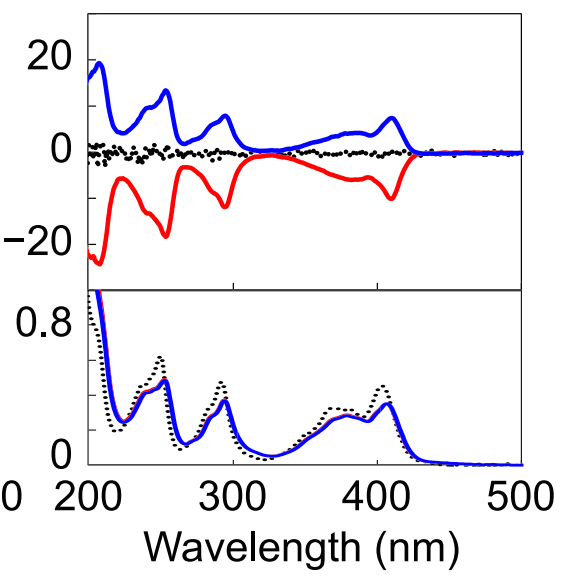

(D) Hyb-helix-TPPS

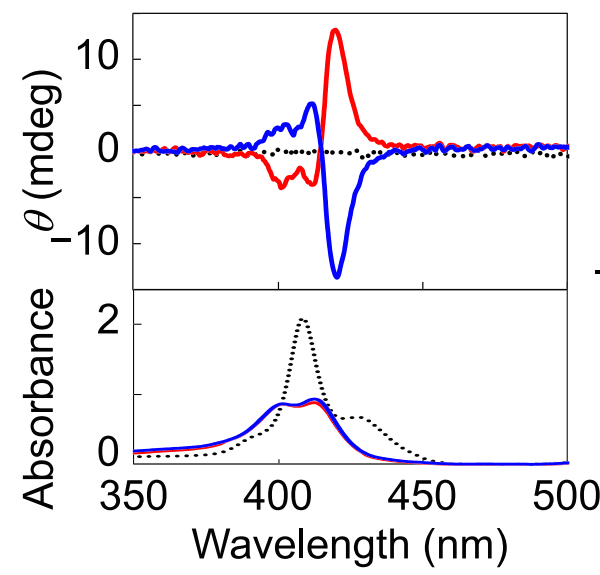

(E) Hyb-helix-SiCor

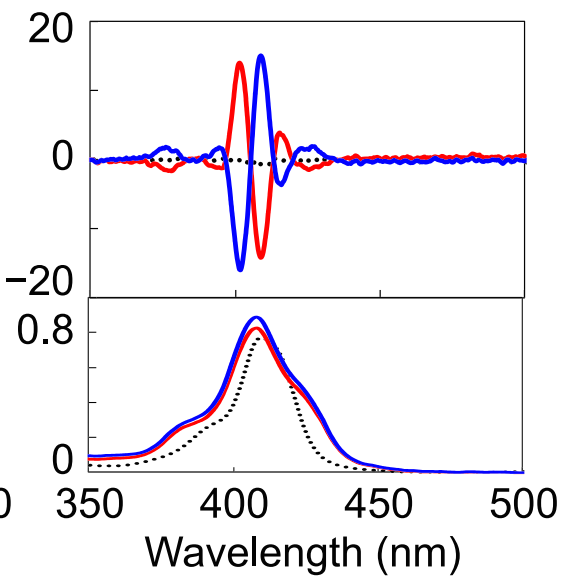

(F) Hyb-helix-PTCTK

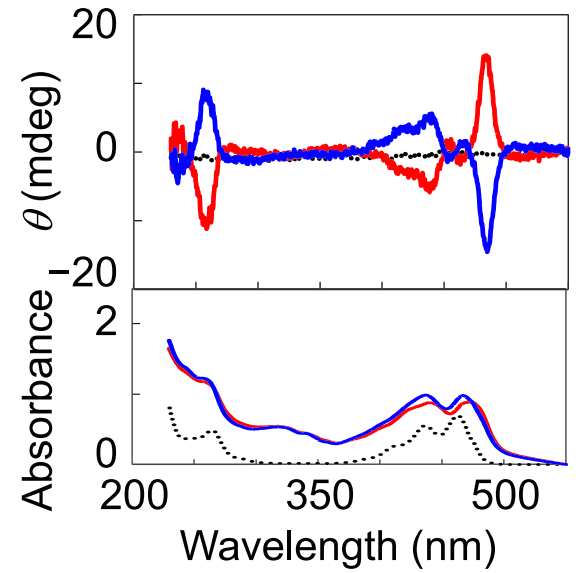

(G) Hyb-helix-IC

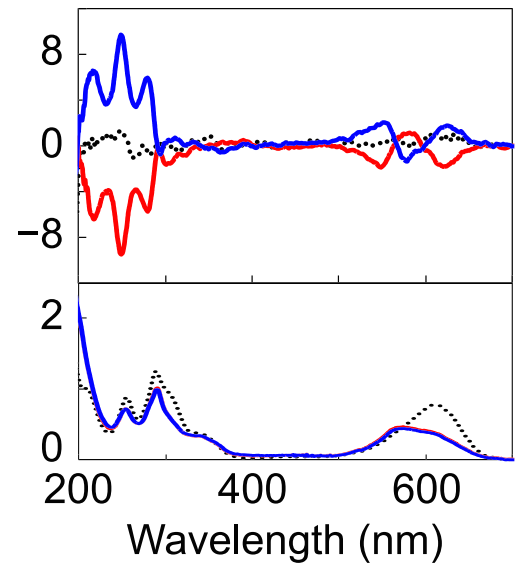

(H) Hyb-helix-CR

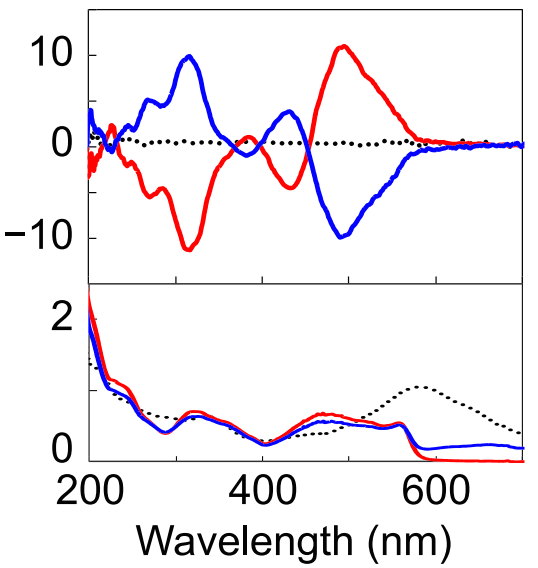

F I G U RE 4 Circular dichroism (CD) (top) and UV-vis absorption (bottom) spectra of (A) PAA aq., (B) PSA aq., (C) Py aq., (D) TPPS aq., (E) SiCor aq., (F) PTCTK aq., (G) IC aq., and (H) CR aq. without (black dotted lines) and with RH- (red lines) and LH- (blue lines) Hyb-helices, respectively. The molar ratio between gemini surfactant and dye molecules ([gemini]/[dye]) are (A) $1 / 1$, (B) $1 / 1$, (C) $1 / 1$, (D) $1 / 0.1$, (E) $1 / 0.1$, (F) $1 / 1$, (G) $1 / 0.8$, and (H) $1 / 1.6$ 
T A B L E $1 \quad g_{\mathrm{CD}}$ values of various achiral organic chromophores mixed with RH- and LH- Hyb-helices

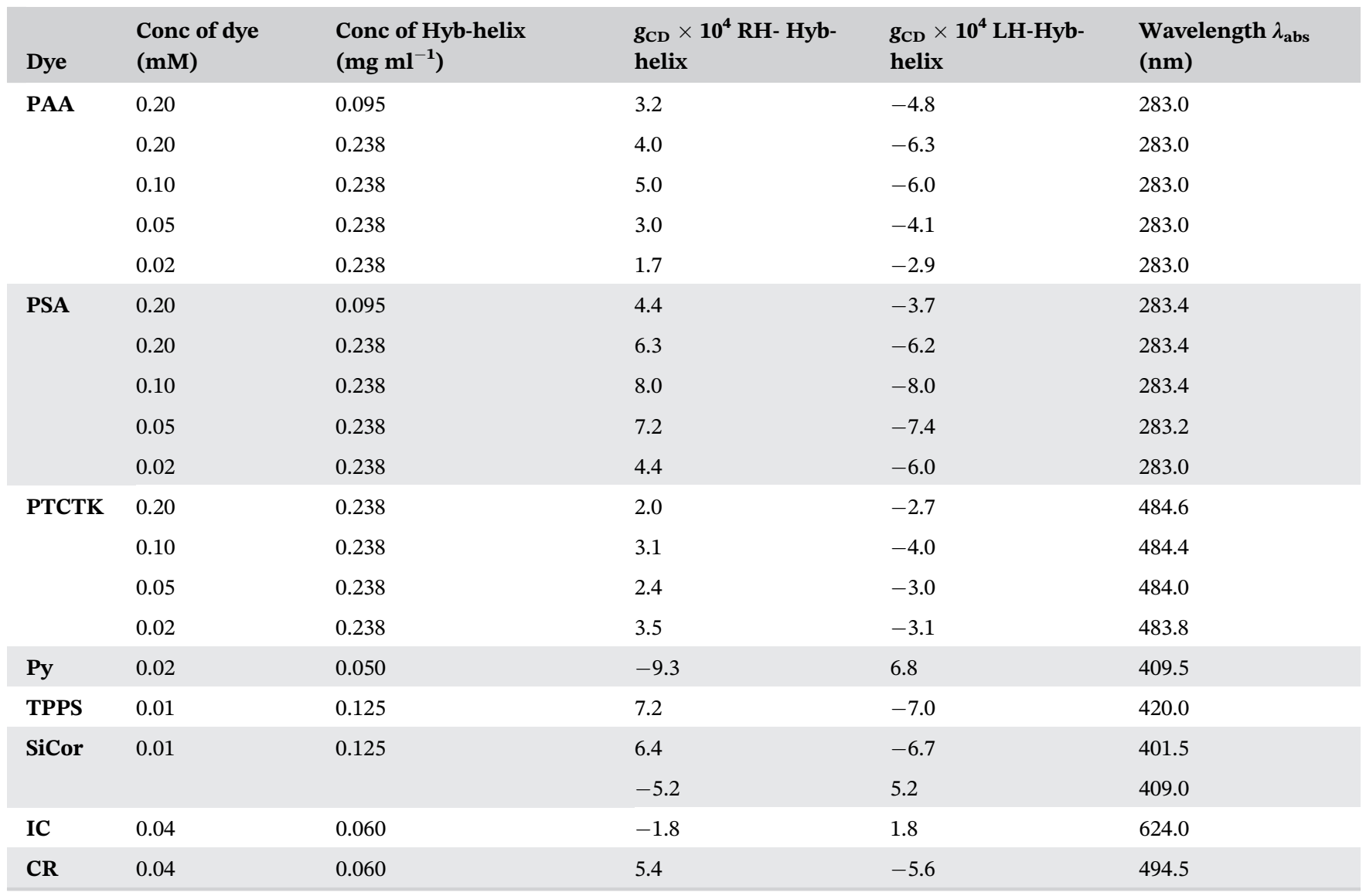

(A) Hyb-helix-PSA

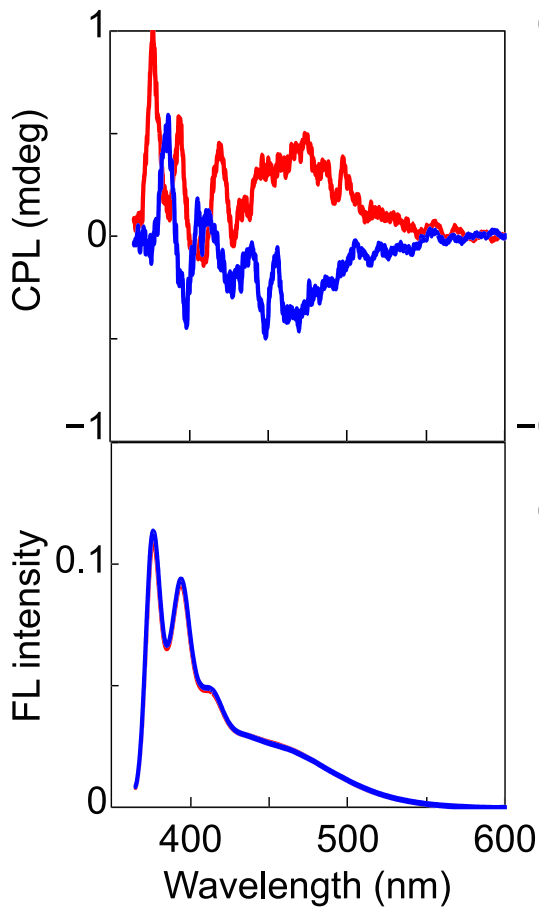

(B) Hyb-helix-PTCTK

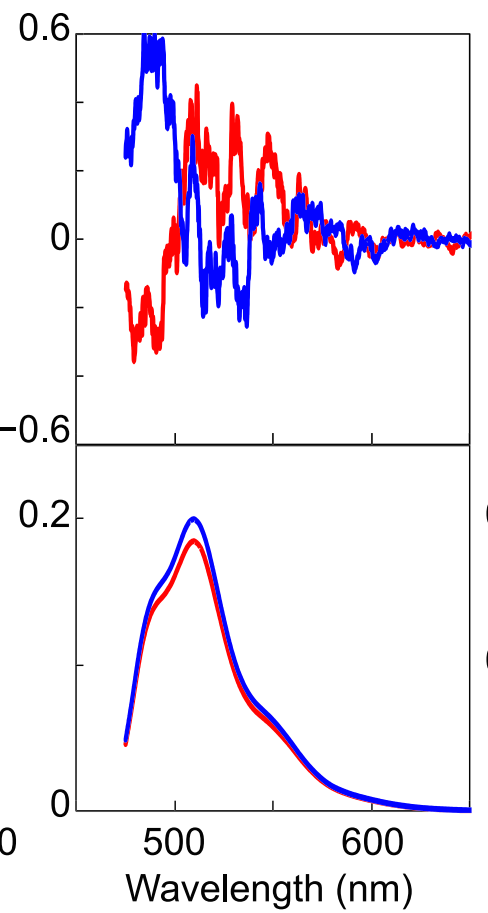

(C) Hyb-helix-TPPS

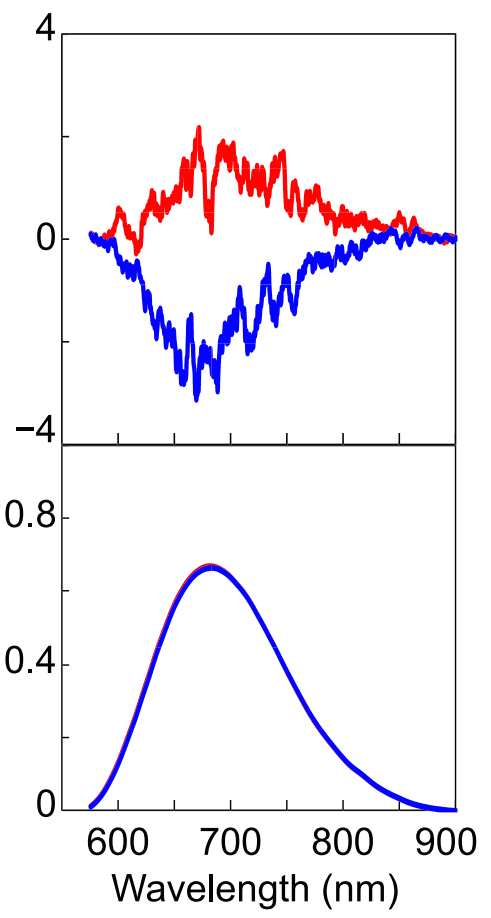

F I G U RE 5 CPL and fluorescence spectra of (A) PSA (ex $340 \mathrm{~nm}$ ), (B) PTCTK (ex $430 \mathrm{~nm}$ ), and (C) TPPS (ex $410 \mathrm{~nm}$ ) in the presence of RH- (red line) or LH- (blue line) handed hybrid helices. The molar ratios between gemini surfactant and dye molecules ([gemini]/[dye]) are (A) $1 / 0.2$, (B) $1 / 2$, and (C) $1 / 0.1$ 


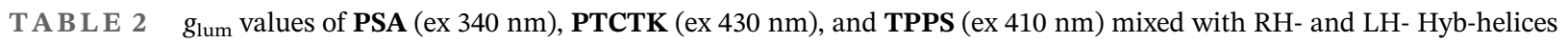

\begin{tabular}{|c|c|c|c|c|c|}
\hline Dye & $\begin{array}{l}\text { Conc of dye } \\
(\mathrm{mM})\end{array}$ & $\begin{array}{l}\text { Conc of Hyb-helix } \\
\left(\mathrm{mg} \mathrm{mL}^{-1}\right)\end{array}$ & $\begin{array}{l}g_{\text {lum }} \times 10^{4} \text { RH-Hyb- } \\
\text { helix }\end{array}$ & $\begin{array}{l}g_{\text {lum }} \times 10^{4} \text { LH- Hyb- } \\
\text { helix }\end{array}$ & $\begin{array}{l}\text { Wavelength } \lambda_{\text {em }} \\
\text { (nm) }\end{array}$ \\
\hline PSA & 0.05 & 0.600 & 13.0 & -13.0 & 470 \\
\hline TPPS & 0.01 & 0.125 & 2.3 & -3.2 & 671 \\
\hline
\end{tabular}

(Figure 5A), making this system one of the rare showing CPL from intermolecular excimers based on nonchiral chromophores. $^{32-34}$ For PTCTK, we can clearly see two peaks, one at $486 \mathrm{~nm}$ and the other around $525 \mathrm{~nm}$. The first peak may be attributed to chirality induction from the chiral supramolecular organization of the gemini molecules to the PTCTK monomer, whereas the second emission peak may originate from PTCTK $J$-aggregates or excimers. In the case of TPPS $^{\mathbf{4}-}$ incorporated into the $\mathrm{RH}-$ and $\mathrm{LH}-$ hybrid helices containing $\mathrm{Cl}-$ as the anion yield positive and negative CPL signals with glum $=2.4$ and $1.6 \times 10^{-4}$, respectively.

The dissymmetry factors $g_{\text {lum }}$ of the three dyes exhibiting ICPL are collected in Table 2. Globally, they are between $10^{-4}$ and $10^{-3}$, and similar to the values of $g_{\text {abs }}$ values shown in Table 1. Although not particularly large compared with those observed from fluid solutions of inherently chiral molecules, it is important to note that the dissymmetry observed here reflects the induction of chirality from a chiral macroscopic object to a molecular dye. Thus, the method described in this study is versatile in that silica-coated molecular assembled nanohelices are capable of inducing chiral signals from a broad panel of anionic nonchiral chromophores and fluorophores.

\section{4 | CONCLUSION}

We report that CD and CPL signals from various families of achiral anionic inorganic or dye molecules can be obtained by co-organizing them with chirally crystallized cationic gemini surfactant molecules in the chiral nanospace within silica nanohelices. In spite of very different molecular structures, all these molecules showed ICD after simply being dissolved in the suspension of silica-coated molecular assembled nanohelices. Some of these luminescent molecules with no chiral auxiliary on chromophore such as TPPS, PSA, and PTCTK also showed ICPL and, in the case of PSA, the ICPL was observed from intermolecular excimer which is a rare observation to date for achiral molecules.

\section{ACKNOWLEDGMENTS}

This work was supported by the Strategic International Collaborative Research Program between Japan Science and Technology Agency in Japan and ANR (ANR-CONACYT-159884) in France, "Japan Society for the Promotion of Science, Grant-in-Aid for Scientific Research (C), Grant 17K05000", Centre National de la Recherche Scientifique and Université de Bordeaux for the "FrenchJapanese International Associated Laboratory, Chiral Nanostructures for Photonic Applications (LIA-CNPA)". It was also supported by European Union's Horizon 2020 research and innovation program under the FET-OPEN project INITIO, grant agreement 828779. Y. O. acknowledges the JSPS Overseas Research Fellowship, the JSPS KAKENHI Grant 19K15376, and SPIRITS 2020 of Kyoto University.

\section{DATA AVAILABILITY STATEMENT}

The data that support the findings of this study are available in the supporting information of this article which can be found in the online version of this article at the publisher's website.

\section{ORCID}

Yutaka Okazaki (i) https://orcid.org/0000-0003-2261-5914 Thierry Buffeteau (10) https://orcid.org/0000-0001-78480794

Fabrizio Caroleo (1) https://orcid.org/0000-0003-1571-3591 Gabriele Magna (1) https://orcid.org/0000-0003-2140-0110 Donato Monti (D) https://orcid.org/0000-0002-6166-8536 Roberto Paolesse (i) https://orcid.org/0000-0002-2380-1404 Manuela Stefanelli (D) https://orcid.org/0000-0001-85638043

Sylvain Nlate (1) https://orcid.org/0000-0002-0300-9081

Emilie Pouget (1) https://orcid.org/0000-0002-3175-6201

Hirotaka Ihara (1) https://orcid.org/0000-0002-3642-8637

Dario M. Bassani (D) https://orcid.org/0000-0002-9278-

1857

Reiko Oda (D) https://orcid.org/0000-0003-3273-8635 


\section{REFERENCES}

1. Knowles WS. Asymmetric hydrogenation. Acc Chem Res. 1983; 16(3):106-112.

2. Noyori R, Takaya H. BINAP: an efficient chiral element for asymmetric catalysis. Acc Chem Res. 1990;23(10):345-350.

3. Ooi T, Maruoka K. Recent advances in asymmetric phasetransfer catalysis. Angew Chem Int Ed. 2007;46(23):4222-4266.

4. Brak K, Jacobsen EN. Asymmetric ion-pairing catalysis. Angew Chem Int Ed. 2013;52(2):534-561.

5. Bodwin JJ, Cutland AD, Malkani RG, Pecoraro VL. The development of chiral metallacrowns into anion recognition agents and porous materials. Coord Chem Rev. 2001;216-217:489-512.

6. Dai Z, Lee J, Zhang W. Chiroptical switches: applications in sensing and catalysis. Molecules. 2012;17(2):1247-1277.

7. Heffern MC, Matosziuk LM, Meade TJ. Lanthanide probes for bioresponsive imaging. Chem Rev. 2014;114(8):4496-4539.

8. Imai Y, Kawano K, Nakano Y, et al. Control of circularly polarized luminescence (CPL) properties by supramolecular complexation. New J Chem. 2008;32(7):1110-1112.

9. Nakamura M, Ota F, Takada T, Akagi K, Yamana K. Circularly polarized luminescence of helically assembled pyrene $\pi$-stacks on RNA and DNA duplexes. Chirality. 2018;30(5):602-608.

10. Li H, Cheng J, Deng H, et al. Aggregation-induced chirality, circularly polarized luminescence, and helical self-assembly of a leucine-containing AIE luminogen. J Mater Chem C. 2015;3 (10):2399-2404.

11. Goto T, Okazaki Y, Ueki M, et al. Induction of strong and tunable circularly polarized luminescence of nonchiral, nonmetal, low-molecular-weight fluorophores using chiral nanotemplates. Angew Chem Int Ed. 2017;56(11):2989-2993.

12. Jiang $\mathrm{Q}, \mathrm{Xu} \mathrm{X}$, Yin $\mathrm{PA}$, et al. Circularly polarized luminescence of achiral cyanine molecules assembled on DNA templates. J Am Chem Soc. 2019;141(24):9490-9494.

13. Han J, Yang D, Jin X, Jiang Y, Liu M, Duan P. Enhanced circularly polarized luminescence in emissive charge-transfer complexes. Angew Chem Int Ed. 2019;58(21):7013-7019.

14. Zhu X, Duan P, Zhang L, Liu M. Regulation of the chiral twist and supramolecular chirality in co-assemblies of amphiphilic L-glutamic acid with bipyridines. Chem A Eur J. 2011;17(12): 3429-3437.

15. Brizard A, Berthier D, Aimé C, et al. Molecular and supramolecular chirality in gemini-tartrate amphiphiles studied by electronic and vibrational circular dichroisms. Chirality. 2009;21 (1E):E153-E162.

16. Hu L, Li K, Shang W, Zhu X, Liu M. Emerging cubig chirality in $\gamma \mathrm{CD}$-MOF for fabricating circularly polarized luminescent crystalline materials and the size effect. Angew Chem Int Ed. 2017;59:4953-4958.

17. Ryu N, Okazaki Y, Hirai K, et al. Memorized chiral arrangement of gemini surfactant assemblies in nanometric hybrid organic-silica helices. Chem Commun. 2016;52(34):5800-5803.

18. Yospanya W, Nishijima M, Araki Y, et al. Near perfect headto-head selectivity on the supramolecular photocyclodimerisation of 2-anthracenecarboxylate with self-organised gemini surfactant bilayers. Chem Commun. 2020;56(69):10058-10061.
19. Okazaki Y, Ryu N, Buffeteau T, et al. Induced circular dichroism of monoatomic anions: silica-assisted the transfer of chiral environment from molecular assembled nanohelices to halide ions. Chem Commun. 2018;54(73):10244-10247.

20. Oda R, Artzner F, Laguerre M, Huc I. Molecular structure of self-assembled chiral nanoribbons and nanotubules revealed in the hydrated state. J Am Chem Soc. 2008;130(44): 14705-14712.

21. Oda R, Huc I, Candau SJ. Gemini surfactants as new, low molecular weight gelators of organic solvents and water. Angew Chem Int Ed. 1998;37(19):2689-2691.

22. Oda R, Huc I, Schmuts M, Candau SJ, MacKintosh FC. Tuning bilayer twist using chiral counterions. Nature. 1999;399(6736): 566-569.

23. Nagao Y, Naito T, Abe Y, Misono T. Synthesis and properties of long and branched alkyl chain substituted perylenetetracarboxylic monoanhydride monoimides. Dyes Pigm. 1996;32(2):71-83.

24. Kaiser TE, Wang H, Stepanenko V, Würthner F. Supramolecular construction of fluorescent $J$-aggregates based on hydrogen-bonded perylene dyes. Angew Chem Int Ed. 2007; 46(29):5541-5544.

25. Gao J, Okazaki Y, Pouget E, et al. Slow kinetic evolution of nanohelices based on gemini surfactant self-assemblies with various enantiomeric excess; chiral segregation towards a racemic mixture. Mater Chem Front. 2021;5(7):3021-3028.

26. Scalabre A, Gutierrez-Vilchez AM, Sastre-Santos A, FernandezLazaro F, Bassani DM, Oda R. Supramolecular induction of topological chirality from nanoscale helical silica scaffolds to achiral molecular chromophores. J Phys Chem C. 2020;124(43): 23839-23843.

27. Stefanelli M, Savioli M, Zurlo F, et al. Porphyrins through the looking glass: spectroscopic and mechanistic insights in supramolecular chirogenesis of new self-assembled porphyrin derivatives. Front Chem. 2020;8:587842. https://doi.org/10.3389/ fchem.2020.587842

28. Occhiuto I, Luca GD, Villari V, et al. Supramolecular chirality transfer to large random aggregates of porphyrins. Chem Commun. 2011;47(21):6045-6047.

29. Castriciano MA, Romeo A, Luca GD, Villari V, Scolaro LM, Micali N. Scaling the chirality in porphyrin J-nanoaggregates. J Am Chem Soc. 2011;133(4):765-767.

30. Manet S, Karpichev Y, Bassani D, Kiagus-Ahmad R, Oda R. Counteranion effect on micellization of cationic gemini surfactants 14-2-14: Hofmeister and other counterions. Langmuir. 2010;26(13):10645-10656.

31. Nostro PL, Fratoni L, Ninham BW, Baglioni P. Water absorbency by wool fibers: Hofmeister effect. Biomacromolecules. 2002;3(6):1217-1224.

32. Ryu N, Kawaguchi T, Yanagita H, et al. Chirality induction on non-chiral dye-linked polysilsesquioxane in nanohelical structures. Chem Commun. 2020;56(53):7241-7244.

33. Inouye $\mathrm{M}$, Hayashi $\mathrm{K}$, Yonenaga $\mathrm{Y}$, et al. $\mathrm{A}$ doubly alkynylpyrene-threaded [4]rotaxane that exhibits strong circularly polarized luminescence from the spatially restricted excimer. Angew Chem Int Ed. 2014;53(52):14392-14396. 
34. Kano K, Matsumoto H, Hashimoto S, Sisido M, Imanishi Y. A chiral pyrene excimer in gamma.-cyclodextrin cavity. J Am Chem Soc. 1985;107(21):6117-6118. 